Андрей Можайский

ORCID: 0000-0003-1112-2858

Институт стратегии развития образования Российской академии образования

Москва, Россия

\title{
ИСПОВЕДЬ В.С. ПЕЧЕРИНА: РЕЦЕПЦИЯ АНТИЧНОЙ ТРАДИЦИИ В ОБРАЗОВАТЕЛЬНОМ ПРОСТРАНСТВЕ XIX ВЕКА ${ }^{1}$
}

\author{
https://doi.org/10.34739/clit.2020.14.07
}

\begin{abstract}
CONFESSION OF VLADIMIR SERGEYEVICH PECHERIN: RECEPTION OF ANTIQUE TRADITION IN THE EDUCATIONAL SPACE OF THE NIENETEENTH CENTURY
\end{abstract}

The article presents the reflection of the antique tradition in the memoirs of the Russian emigrant of the nineteenth century V.S. Pecherin. Written in epistolary form these memoirs are confessional in their character and one can traced a strong classical influence, formed by his education. Particular attention is given to Berlin as educational space, where V.S. Pecherin studied at the university and regularly visited the Altes Museum. There is a close relationship between the influence of Ancient Greek art V.S. Pecherin saw in the museum and his cultural and aesthetic views presented in his memoirs. According to the author, V.S. Pecherin presented himself as the second Xenophon wandering around Europe and expelled from his homeland in absentia. The title of the memoir Apologia pro vita mea, probably, has as its prototype both the Socratic tradition and the Christian tradition, especially expressed in the title of the work Apologia pro vita sua by John Henry Newman.

Keywords: educational space, Vladimir Sergeyevich Pecherin, classical tradition, antique tradition, Xenophon, Socrates, Altes Museum, The Berlin Athlete, Playing knucklebones, John Henry Newman

Замогильные записки Владимира Сергеевича Печерина ${ }^{2}$ первоначально написаны в виде писем, частью к своему племяннику,

${ }^{1}$ Исследование выполнено за счет гранта Российского научного фонда (проект № 18-78-10001).

2 Владимир Сергеевич Печерин (1807-1885) - поэт, ученый, мемуарист, профессор Московского университета. Эмигрировал из России и после скитаний за границей принял католичество, осел в Ирландии, где скончался в 1885 г. О жизни В.С. Печерина в Ирландии см.: Е. MacWhite, Vladimir Pecherin, 1807-1885: The First Chaplain of the 
а частью к университетскому другу - Ф.В. Чижову. К сожалению, попытки В.Ф. Чижова опубликовать письма В.С. Печерина не увенчались успехом и рукопись впервые была опубликована лишь в 1932 году 3 . Эти записки несомненно носят характер исповеди, поскольку В.С. Печерин писал Ф.В. Чижову 13 августа 1871 года о своей книге:

Это некоторого рода духовное завещание - это «Apologia pro vita mea» - моя защита перед Россиею, особенно перед новым поколением. Какая ни будет участь этих записок, но все ж таки, мне кажется, что они могли бы быть предметом любопытного психологического исследования. Они представляют явление самостоятельного русского развития, я говорю русского, потому что подобное развитие невозможно было бы ни в Англии, ни во Франции, ни в Германии...4.

Эта Apologia pro vita mеa (Оправдание моей жизни) является искренним сочинением, имеющим целью исповедоваться. В процитированном выше письме мы видим античную традицию, которой была пропитана вся жизнь Владимира Сергеевича, причудливым, но органичным образом соединившаяся с христианским наследием. С одной стороны, в названии и смысловой нагрузке прослеживаются Апология Сократа Платона и, особенно,

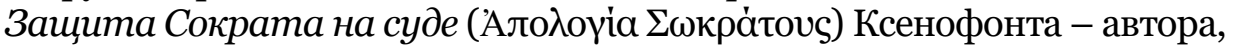
который, как и сам В.С. Печерин, стал отчасти добровольным изгнанником, странствовавшим по разным областям Древнего Востока, Эгейского и Причерноморского региона и окончившим жизнь вдали от своих родных Афин. Произведения этого автора,

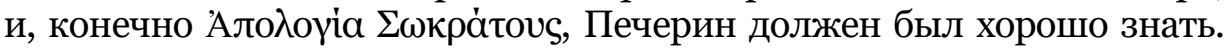
Он сам пишет об этом в своих записках касательно бедственного пребывания в 1838 году в г. Льеже:

Это были первые деньги, заработанные моим честным трудом. Хозяин тотчас подбежал и подал мне счет. Я с ним расплатился и у меня еще осталось два франка с небольшим. После этого я вырос несколькими вершками, выпрямился, прибодрился. Я чувствовал, что я уже не бродяга, не нищий, а порядочный человек, имеющий деньги в кармане и платящий свои долги! В избытке блаженства, с переполненным сердцем я пошел прогуляться и зашел на толкучий рынок в Hôtel de ville купить себе - что вы думаете? пряник? или

Mater Hospital, Dublin, and the First Russian Political Emegré, „Studies: An Irish Quarterly Review”, Vol. 61, No. 241 (Spring, 1972), pp. 23-40.

3 Л.Б. Каменев, Введение, [в:] В.С. Печерин, Замогильные записки, Калинин 1932, с. 4.

4 В.С. Печерин, Оправдание моей жизни: памятные записки, „Наше наследие” 1989, № 1, c. 62. 
сосульку? - нет! не угадали! я зашел купить - стереотипное издание греческого классика - помнится Ксенофонта Memorabilia Socratis, т.-е. первое, что мне попалось под руку. С этою покупкою я воротился домой и бросился на постель5

Воспоминания о Сократе Ксенофонта сами являются своего рода апологией великому мудрецу, хоть В.С. Печерин и отзывается о нем далее с христианской позиции как о «пошлом старике Сократе»6. Действительное отношение В.С.Печерина к фигуре Сократа раскрывается здесь же, в этом же отрывке из его записок, где он сравнивает своего уважаемого благодетеля капитана Файета с Сократом: «У капитана был камердинер, лихой парень 22-х лет кровь с молоком - бельгийского происхождения - имени и отечества не помню. Капитан был Сократ; а камердинер был, положим, нечто в роде Алкивиада»7. Отметим, что в библиотеке В.С. Печерина, которую тот завещал Московскому университету и которая сейчас хранится в Отделе редких книг и рукописей Научной библиотеки МГУ, содержится греческих книг: пятьдесят пять томов древних авторов, три издания Нового Завета (+ два греческо-английских словаря) ${ }^{8}$. А.И.Любжин также отмечает, что в данной библиотеке находится четыре отдельных книги Ксенофонта и полный Платон с изданиями отдельных произведений 9 . Однако, как уже отмечалось, в текстах записок В.С.Печерина наблюдается симбиоз античного и христианского наследия, причем порой весьма позднего христианского наследия, современником которого являлся сам B.C. Печерин. Сама латинская фраза «Apologia pro vita mea», которой B.С.Печерин характеризует свои записки, имеет современный B.C. Печерину прототип. Дело в том, что Джон Генри Ньюмен -

\footnotetext{
5 В.С. Печерин, Замогильные..., ор. cit., с. 69.

${ }^{6}$ Ibidem.

7 Ibidem, c. 68.

8 А.И. Любжин, Античные авторы в библиотеке В.С. Печерина, [в:] Индоевропейское языкознание и классическая филология - XVII (чтения памяти И.М. Тронского). Материалы Международной конференции, проходивщей 24-26 июня 2013 г., СанктПетербург 2013, с. 563-564.

9 Кроме того, помимо обозначенных авторов, как отмечает А.И. Любжин, в собрании В.С. Печерина присутствуют все трагики, и Аристофан, притом полные собрания для каждого дополняются отдельными изданиями пьес, Фукидид (2 издания) и примыкающий к ним Геродот (полное издание и отдельно I книга), Эсхин (только одна речь против Ктесифонта с примыкающей речью Демосфена, который представлен и собранием сочинений), и только Аристотель из фигур первого ряда представлен лишь одной книгой. Отсутствуют: Гомер, Гесиод, отдельные издания поэтов архаической и александрийской эпохи; есть Исократ, историки эллинистической и римской эпохи Полибий и Арриан, Эпиктет, Лукиан (также - полное собрание и избранные диалоги), присутствует сборник эпиграмм. Проанализирован также латинский состав библиотеки. Подробнее см.: А.И. Любжин, оp. cit., с. 559-570.
} 
центральная фигура в религиозной жизни Викторианской Англии известный своим переходом из англиканской церкви в католическую (напомним, что В.С. Печерин сам перешел из православия в католичество), назвал свою автобиографию, вышедшую в 1865 г. Apologia pro vita sua (Оправдание своей жизни). Представляется, что B.C. Печерин не мог не читать эту работу, учитывая его сан и жизненный опыт, включая присутствие в религиозной жизни Англии и интерес к проповедям.

Но, вернемся к первому изданию мемуаров В.С. Печерина, озаглавленных редакцией 1932 г. как Замогильные записки. П.Г. Горелов в предисловии к изданию мемуаров в журнале „Наше наследие” за 1989 г. (№ 1-3), отмечает, что «название Замогильные записки, избранное редакцией 1932 года, не совсем удачно: так озаглавлена только часть мемуаров, отражающая временное настроение автора»10. Однако, даже если Apologia pro vita mea является более объективным названием, то «временное настроение», отраженное в названии Замогильные записки, также отсылает нас к классическому образованию. Дело в том, что именно так назвал свои мемуары, вышедшие в 1848 году один из властителей дум поколения Печерина - Франсуа Рене де Шатобриан (1768-1848). В.А. Мильчина во вступительной статье к русскому изданию Замогильнъх записок Шатобриана отмечает, что «в XIX веке историк Токвиль сравнивал их (Замогильных записок - А. М.) автора с классиками - Гомером и Тацитом»11. И это сравнение не случайно, поскольку произведения Шатобриана пестрят античностью, особенно Путешествие из Парижа в Иерусалим и из Иерусалима в Париж, через Грецию и обратно через Еzuпет, Варварию и Испанию (Itinéraire de Paris à Jérusalem et de Jérusalem à Paris, en allant par la Grèce et revenant par l'Égypte, la Barbarie et l'Espagne, 1811) или Этюды или исторические речи о падении Римской империи, рождении и развитии христианства и вторжении варваров (Études ou discours historiques sur la chute de l'Empire romain, la naissance et les progrès du christianisme et linvasion des barbares, 1831). В.А. Мильчина считает, что мемуары В.С. Печерина, «хотя имя Шатобриана в тексте не упоминается», носят полемический антишатобриановский характер в том отношении, что он не признает добровольную «замогильную» позицию Шатобриана и мечтает напечататься на родине при жизни, а поэтому «он иронизирует над „высоким эстетическим характером” посмертных мемуаров - то есть именно над той позицией, которую

${ }^{10}$ В.С. Печерин, Оправдание..., ор. cit., с. 62.

${ }^{11}$ В.А. Мильчина, Эпопея человеческого сознания, [в:] Франсуа Рене де Шатобриан. Замогильные записки, Москва 1995, с. 7. 
сознательно и добровольно избрал для себя на склоне лет Шатобриан»12. Мы не отказываем Печерину в такой иронии, поскольку его тексты пронизаны иронией по отношению ко многому: к себе, к России, Западу, Сократу, поэтому, может быть, он иронизирует и по отношению к мемуарам Шатобриана. Однако Печерин, все же, упоминает в своих записках Шатобриана, когда, опять-таки, иронично описывает поляка Потоцкого: «Потоцкий был самый идеал польского шляхтича: долговязый, худощавый, бледный, белобрысый, с длинными повисшими усами, с физиономией Костюшки т.е. une espèce de singe, как сказал Шатобриан ${ }^{13}$. Таким образом, В.С. Печерин знал произведения Шатобриана настолько, что в данном случае мог процитировать оригинал. Соответственно, мы подходим к теме образовательного пространства, в котором вращался В.С. Печерин и которое было в своей классичности общим с образовательным пространством европейских центров, порождением которого, пусть немного ранее, явился и Шатобриан.

Как считал сам В.С. Печерин, родившись в России у него было мало шансов получить действительно европейское образование:

Моя судьба висела на волоске. Не будь мать, которая непременно хотела мне дать наилучшее воспитание, отец давно уж бы записал меня в военную службу, а там я уж несомненно бы погиб и физически, и нравственно. Я все просился в университет. Отец однажды сказал мне: «Вот я тебе дам 500 рублей, поезжай в Харьков и купи себе диплом». Боже милосердный! Можете себе представить, с каким негодованием я принял это предложение. Я не диплома искал, а науки.

Но как же это рисует русские нравы, русский взгляд на вещи! В других странах стараются развить человека, а у нас об одном хлопочут - как бы сделать чиновника, а после этого хоть трава не расти ${ }^{14}$.

Несмотря на все это, В.С. Печерин двигался к своей цели и в 1829 году поступил в Петербургский университет. Однако в те годы это достижение Печерина не могло равняться с основательным европейским образованием, которое можно было получить в престижных европейских университетах. Как отмечает Н.М. Первухина-Камышникова, цитируя В.С. Печерина:

Петербургский университет в 1829-1831 годах от Московского отличался казенным духом и довольно низким уровнем преподавания. Впоследствии, прожив много лет в Англии, Печерин

${ }^{12}$ Ibidem, c. 8.

13 В.С. Печерин, Замогильные..., ор. cit., с. 101-102.

14 Ibidem, c. 35. 
заметит, что его любимый профессор Грефе, с которым он занимался переводами греческих авторов, «хоть академик и немец, а все ж таки едва ли бы годился быть маленьким доцентом в Оксфорде». Если Герцен до конца жизни вспоминал с восторгом студенческие годы, то Печерин запомнил, что «в преподавании не было ничего серьезного: оно было ужасно поверхностно, мелко, пошло. Студенты заучивали тетрадки профессоров, да и сам профессор преподавал по тетрадкам, им же зазубренным во время оно ${ }^{15}$.

В 1831 г. В.С. Печерин закончил университет и в скором времени в печати появляются его стихотворные переводы, среди которых особое место занимают переводы из собрания древнегреческой лирики. Н.М. Первухина-Камышникова, приводя в своей работе соответствующую библиографию, отмечает, что «в 1832 году печатались его переводы Из греческой антологии в Невском альманахе Е. В. Аладьина, в Комете Бель М.П. Погодина» ${ }^{16}$. Писал В.С. Печерин и научные работы. Еще в 1831 г. он напечатал в „Сыне отечества" статью о трагедиях Софокла"17, которую М.О. Гершензон охарактеризовал как «очень замечательную вообще для того времени и особенно для молодого филолога» ${ }^{18}$. Кроме того, следует отметить, что в 1835 г. в „Журнале Министерства народного просвещения” вышла аннотация открытой лекции В.С. Печерина в Петербургской академии наук, посвященной знаменитой речи Перикла над могилой павших воинов, переданной Фукидидом (Thuc. 2. 35-46)19. Уже после отъезда Печерина из России, в 1838 году была напечатана статья $O$ әреческой эпиграмме и восемь переводов (без подписи) в «Современнике». Печерина как переводчика сравнивали с Жуковским и Батюшковым. В 1935 г. в сборнике Лирика древней Эллады го были переизданы его переводы из Мелеагра Гадарского, Асклепиада Самосского, из Алкея, Феодорида и Антифила Византийского. Поэтической ценности его переводов сопутствовала

15 Н.М. Первухина-Камышникова, В.С. Печерин: Эмигрант на все времена, Москва 2006, с. 37-38. Следует отметить, что Э.Д. Фролов в работе, посвященной русской науке об античности, весьма посредственно характеризует преподавание, к примеру, всеобщей истории в университетах того времени см.: Э.Д. Фролов, Русская наука об античности (историографические очерки), Санкт-Петербург 1999, с. 143-145.

${ }^{16}$ Н.М. Первухина-Камышникова, op. cit., с. 44.

17 В.С. Печерин, Взгляд на Трагедии Софокла: Антигона и Аякс, „Сын Отечества”, XVIII, 1831, c. 351-361.

18 М.О. Гершензон, Жизнь В. С. Печерина, Санкт-Петербург 2013, с. 381.

19 E. MacWhite, Towards a Biography of Father Vladimir S. Pecherin (1807-1885): A Progress Report and Bibliography, „Proceedings of the Royal Irish Academy: Archaeology, Culture, History, Literature", Vol. 80 C (1980), p. 121.

20 Лирика древней Эллады, ред. Я. Голосовкер, Москва-Ленинград 1935. 
метрическая и смысловая верность оригиналу, они не уступают переводам лучших поэтов-современников ${ }^{21}$.

Однако, главное свое образование Печерин получил, попав в действительное образовательное пространство европейского города XIX века, а именно в Берлин, куда в 1833 г. он был отправлен в двухлетнюю командировку «с ученой целью на предмет приготовления к профессорскому званию»22. М.О.Гершензон отмечает также, что по дороге в Берлин Печерин остановился в Дерпте

(...) где „товарищи” встретили его с отверстыми объятиями: Это были командированные одновременно с ним за границу, которые вскоре затем и сами тронутся в путь (Пирогов, Редкин, М.С. Куторга и др.); он читал им свои стихи, шампанское кипело в бокалах, «в немного минут много было сказано»; его проводили за город на почтовых и даже прибавили денег к его, очевидно скудному, запасу23.

Для нашей темы весьма примечательным моментом является упоминание В.С. Печериным Михаила Семеновича Куторги будущего основателя русской исторической науки об античности.

В Берлинском университете В.С. Печерин слушал лекции известнейших профессоров, включая учеников великого Гегеля Михелета (по философии) и Стеффенса (по философии религии). Однако, к сожалению, исследователи практически не упоминают, что не менее значимы для В.С. Печерина были лекции Августа Бёка, который читал методологию филологических наук, не имеющую, по словам В.С. Печерина, ничего общего с той «жалкой» филологией, «которая занимается буквами, точками и запятыми древних писателей» 24 . Слушал Августа Бёка и товарищ В.С. Печерина, историкклассик М.С. Куторга25. Последний также посещал занятия историков Леопольда фон Ранке и Фридриха фон Раумера. Предполагаем, что занятия этих видных историков мог посещать и В.С. Печерин. По крайней мере их имена и идеи могли обсуждаться на ежедневных обедах с соотечественниками в ресторане Гильгендорфа, о которых (на основании документов В.С. Печерина) упоминает М.О. Гершензон. После этих обедов В.С. Печерин идет в музей, где почти каждый день проводит два часа, главным образом, в отделении античной скульптуры, и иногда «совершенно забывается в наслаждении, смотря

\footnotetext{
${ }^{21}$ Н.М. Первухина-Камышникова, В.С. Печерин: Эмигрант на все времена, Москва 2006, c. 44.

22 M.O. Гершензон, ор. cit., с. 396.

23 Ibidem, c. 398.

24 Ibidem, c. 400-401.

${ }_{25}$ A. Yu. Mozhajsky, In the Footsteps of M.S. Koutorga, the First Russian Explorer of Boiotia, “Teiresias”, Vol. 49 (part1), 2019, p. 2.
} 
на эти идеальные формы человеческой красоты» ${ }^{26}$. Таким образом, образовательное пространство Берлина для В.С. Печерина и М.С. Куторги включало, как минимум, три точки: Берлинский университет, где они посещали занятия, ресторан Гильгендорфа, где они обсуждали свои занятия и текущее состояние дел, а также музей. Что касается музея, то имеется в виду «Старый» музей Берлина (Altes Museum), называвшийся до 1845 г. «Королевским». Строительство музея было окончено в 1830 г., соответственно, незадолго до приезда Печерина. Именно в этом музее с 1830 г. хранится главная часть королевской прусской коллекции искусства - античные скульптуры, которые традиционно располагаются на главном этаже музея, в то время как «Antiquarium» на нижнем этаже позволял посетителю XIX века восхититься древними вазами, артефактами из бронзы и другими драгоценными объектами из редких материалов ${ }^{27}$.

Благодаря недавно вышедшему каталогу античных коллекций Берлинских музеев (The Antikensammlung, Berlin 2016), мы можем определить некоторые статуи, которые видел Печерин в Altes Museum. Среди них мы находим «Берлинского Атлета» (Sk 471) - мраморную римскую копию бронзового греческого оригинала, созданного последователями Лисиппа (ок. 310-280 гг. до н.э.). Отметим, что в год (1833 г.) отъезда в Берлин В.С. Печерин опубликовал в „Комете Белы” перевод эпиграммы Из греческой антологии под названием Статуя Александра Великого ${ }^{28}$, где говорит о творении Лисиппа. Таким образом, статуя «Берлинского Атлета» должна была особенно привлекать В.С. Печерина, поскольку в ней воплощен «взор огненный, мужества полный» из перевода Печерина. Эта статуя была приобретена еще в XVIII веке в Риме у Барталамео Кавацеппи, который дополнил ее утраченные части. В таком отреставрированном виде эта статуя стояла напротив Нового дворца в Потсдаме. Однако, большинство дополнений Кавацеппи были обновлены немецким скульптором Кристианом Даниэлем Раухом во время подготовки музея к открытию в 1830 году: постамент, искусно сделанную круговую заплату, которая покрывает скол между шеей и торсом, а также предплечья. Подходящие атрибуты были добавлены рукам в соответствии с древними моделям: в правой руке находился сосуд для масла, а левая рука была открыта так, будто атлет собирается налить в нее это масло. Именно такой видели эту статую В.С. Печерин и М.С. Куторга. Однако, сейчас, после 1997 г., была оставлена только правая рука, поскольку она может близко соответствовать оригиналу.

\footnotetext{
${ }^{26}$ M.О. Гершензон, op. cit., c. 401.

27 A. Scholl, The Antikensammlung: 350 years of classical antiquity in Berlin, [in:] The Antikensammlung, Berlin 2016, p. 7.

${ }_{28}^{8}$ В.С. Печерин, Статуя Александра Великого, „Комета Белы” 1833, с. 257.
} 
Тем не менее, первоначально статуя, вероятно, посвящалась победителю в боксерском поединке, а, в таком случае, обе руки должны были быть перевязаны кожаными ремнями, которые носили боксеры. Уменьшенные пропорции головы по сравнению с работами скульпторов до него и увеличенная длина ног статуи напоминают работы знаменитого скульптора Лисиппа из Сикиона. На наш взгляд, статуи этой школы сильно повлияли на восприятие красоты B.C. Печериным, поскольку, как передает Плиний Старший:

Передают, что в искусство скульптуры из меди он (Лисипп - А.М.) внес наибольший вклад, выделяя волосы, головы делая меньше, чем делали прежние художники, тела стройнее и сухощавее, чтобы благодаря этому статуи казались выше (...) и говорил (Лисипп - А. М.), что они (прежние художники - А. М.) изображают людей такими, какие они есть, а он - такими, какие они представляются (пер. Г.А. Тароняна) ${ }^{29}$.

Это идеалистическое представление людей, в особенности женщин, будет раскрыто В.С. Печериным на страницах его записок. Например, в главе «Три женщины», описывая третью женщину на пороге смерти, В.С. Печерин отмечает:

Сколько я видел миленьких личек, которых ни разврат, ни болезнь не могли исказить! Какие роскошные, длинные густые волнистые волосы, такие косы, что какая-нибудь дама заплатила бы за них весом золота. Одна из этих несчастных жертв умерла на руках у меня. Перед смертью она сказала мне: «Поцелуйте меня в щеку, и я умру счастливой». Я в то время (этому 12 лет) был строгим блюстителем духовных приличий: мне показалось это неприличным, и я дал ей поцеловать холодное медное распятие (...) Какое-то облако грусти омрачило ее лицо: она как-будто чувствовала себя отверженною, презренною. До сих пор не могу забыть я, и до сих пор мне жаль, что не исполнил ее просьбыз

Печерин обращает внимание на волосы этой женщины и на ее грусть. Другой отрывок из записок В.С. Печерина имеет прямую параллель с античной статуей, которую он видел в Берлине:

Я сначала едва мог разглядеть, что в глубине комнаты на софе лежало милое дитя каких-нибудь 17 лет с длинными - небрежно разбросанными русыми локонами, исхудавшая, бледная и с роковым

29 Плиний Старший, Естественная история, кн. 34.http://annales.info/ant_lit/plinius/ 34.htm, [дата доступа: 12.11.2019].

зо В.С. Печерин, Оправдание моей жизни: памятные записки, „Наше наследие” 1989, № 3, c. 114-115. 
румянцем на щеках. Она едва могла приподняться, чтобы приветствовать меня. С детскою простотою она рассказала мне всю свою историю (...) Через три дня она умерлаз ${ }^{1}$.

В «Старом» музее есть скульптура (Sk 494), которую должен был видеть В.С. Печерин и которая отражает этот рассказ. Речь идет об Играющей в кости (ок. 140 г. н.э.). Эта мраморная скульптура была найдена в Риме в 1732 г. и появилась в Германии в 1742 г. Увлеченная игрой в кости, молодая девушка сидит на земле, опираясь на левую руку. Этот тип статуи был разработан в эллинистический период и часто копировался в римском искусстве. Мотив спадающей одежды с плеча и обнаженной груди призван был показать физическую красоту молодой девушки и часто использовался в греческой иконографии при изображении богини любви Афродиты. Однако голова статуи была добавлена к римской копии греческой модели позднее, ок. 200 г. до н.э. Мы можем видеть весьма печальное лицо этой девушки, как раз примерно того возраста, который выше описал B.С. Печерин, но главное, что роднит данный образ с приведенным отрывком, то, что эта скульптура, вероятнее всего, использовалась как надгробный памятник девушке, которая умерла очень молодой. Он выражает трагедию ее преждевременной смерти: девушка, играя в кости, представлена почти ребенком, но ее спадающая одежда уже показывает взрослую красоту. Именно этот мотив подчеркивает и В.С. Печерин в приведенном отрывке, когда совсем юная девушка, почти ребенок, при этом была уже достаточно взрослой, чтобы погибнуть от первой несчастной любви.

Переходя к заключению отметим, что «берлинский период» жизни В.С. Печерина имел решающее значение в формировании его взглядов, причем не только общественно-политических ${ }^{32}$, но и культурно-эстетических. Характеризуя классическое образовательное пространство Европы того времени еще В.П. Бузескул отмечал:

То была пора, когда, среди наступившего после долгих наполеоновских войн мира, различные нации Европы вступили как бы в соревнование между собою на научном поприще; но в сфере историко-филологических наук первое место принадлежало тогда, бесспорно, Германии. Здесь мы видим кипучую деятельность, обилие

\footnotetext{
${ }^{31}$ В.С. Печерин, Замогильные записки, ор. cit., с. 98-99.

32 Берлинский период В.С. Печерина оказал прямое влияние на его общественнополитические взгляды и в поэме Торжество смерти Печерин изобразил Николая I в образе самосского тирана Поликрата, см.: E. MacWhite, Vladimir Pecherin, 1807-1885: The First Chaplain of the Mater Hospital, Dublin, and the First Russian Political Emegré, „Studies: An Irish Quarterly Review”, Vol. 6o, No. 239/240 (Autumn-Winter, 1971), p. 301.
} 
талантов. Корифеями в области изучения древности в начале XIX в. являются Вольф, Нибур и потом Бёк33.

Таким образом, В.С. Печерин окунулся в самый центр европейской образованности того времени и стал «русским европейцем», что, по словам В.Г. Щукина, означает человека, «который получил европейское воспитание, усвоил европейскую манеру поведения, который по-европейски обучен наукам»34. Классическое наследие было сердцевиной этой европейской образованности и выражалось для В.С. Печерина в образовательном пространстве Берлина через университетские курсы, товарищеские обеды, а также через музейную педагогику в Altes Museum. Этот образовательный опыт нашел отражение на страницах писем B.С. Печерина, которые издатели собирательно называли Замогильные записки или Apologia pro vita теа - Оправдание моей жизни.

\section{Литература}

MacWhite E., Towards a Biography of Father Vladimir S. Pecherin (1807-1885): A Progress Report and Bibliography, "Proceedings of the Royal Irish Academy: Archaeology, Culture, History, Literature", Vol. 80C (1980), pp. 109-158.

MacWhite E., Vladimir Pecherin, 1807-1885: The First Chaplain of the Mater Hospital, Dublin, and the First Russian Political Emegré, "Studies: An Irish Quarterly Review”, Vol. 60, No. 239/240 (Autumn-Winter, 1971), pp. 295-310.

MacWhite E., Vladimir Pecherin, 1807-1885: The First Chaplain of the Mater Hospital, Dublin, and the First Russian Political Emegré, "Studies: An Irish Quarterly Review”, Vol. 61, No. 241 (Spring, 1972), pp. 23-40.

Mozhajsky A. Yu., In the Footsteps of M.S. Koutorga, the First Russian Explorer of Boiotia, "Teiresias", Vol. 49 (part1), 2019, pp. 1-19.

Scholl A., The Antikensammlung: 350 years of classical antiquity in Berlin, [in:] The Antikensammlung, Berlin 2016, pp. 7-18.

Бузескул В.П., Введение в историю Греции. Обзор источников и очерк разработки греческой истории в XIX и в начале XX в., Санкт-Петербург 2005.

Гершензон М.О., Жизнь В. С. Печерина, Санкт-Петербург 2013.

33 В.П. Бузескул, Введение в историю Греции. Обзор источников и очерк разработки греческой истории в ХІХ и в начале ХХ в., Санкт-Петербург 2005, с. 299.

34 В.Г. Щукин, Русское западничество. Генезис - сущность - историческая роль, Лодзь 2001, с. 36. 
Каменев Л.Б., Введение, [в:] Печерин В.С. Замогильные записки, Калинин 1932, с. 3-13.

Лирика древней Эллады, ред. Я. Голосовкер, Москва-Ленинград 1935.

Любжин А.И., Античные авторы в библиотеке В.С. Печерина, [в:] Индоевропейское языкознание и классическая филология - XVII (чтения памяти И.М. Тронского). Материаль Международной конференции, проходивщей 24-26 июня 2013 г., Санкт-Петербург 2013, с. 559-570.

Мильчина В.А., Эпопея человеческого сознания, [в:] Франсуа Рене де Шатобриан. Замогильные записки, Москва 1995, с. 5-17.

Первухина-Камышникова Н.М., В.С. Печерин: Эмигрант на все времена, Москва 2006.

Печерин В.С., Взгляд на Трагедии Софокла: Антигона и Аякс, “Сын Отечества”, Т. XVIII, 1831, с. 351-361.

Печерин В.С., Замогильные записки, Калинин 1932.

Печерин В.С., Оправдание моей жизни: памятные записки, "Наше наследие” 1989, № 1, с. 61-77.

Печерин В.С., Оправдание моей жизни: памятные записки, "Наше наследие" 1989, № 3, с. 97-117.

Печерин В.С., Статуя Александра Великого, “Комета Белы” 1833.

Плиний Старший, Естественная история, кн. 34. http://annales.info/ ant_lit/plinius/34.htm, [дата доступа: 12.11.2019].

Фролов Э.Д., Русская наука об античности (историографические очерки), Санкт-Петербург 1999.

Щукин В.Г., Русское западничество. Генезис-сущность-историческая роль, Лодзь 2001.

\section{References}

Buzeskul V.P., Vvedenie v istoriû Grecii. Obzor istočnikovi očerk razrabotki grečeskoj istorii $v$ XIX i v načale XX v., Sankt-Peterburg 2005.

Frolov È.D., Russkaâ nauka ob antičnosti (istoriografičeskie očerki), SanktPeterburg 1999.

Geršenzon M.O., Žizn' V. S. Pečerina, Sankt-Peterburg 2013.

Kamenev L.B., Vvedenie, [v:] Pečerin V.S. Zamogil'nye zapiski, Kalinin 1932, s. 3-13.

Lirika drevnej Èllady, red. Â. Golosovker, Moskva-Leningrad 1935.

Lûbžin A.I., Antičnye avtory v biblioteke V.S. Pečerina, [v:] Indoevropejskoe âzykoznanie $i$ klassičeskaâ filologiâ - XVII (čteniâ pamâti I.M. Tronskogo). Materialy Meždunarodnoj konferencii, prohodivšej 24-26 iûnâ 2013 g., Sankt-Peterburg 2013, s. 559-570.

MacWhite E., Towards a Biography of Father Vladimir S. Pecherin (1807-1885): A Progress Report and Bibliography, "Proceedings of the Royal Irish Academy: Archaeology, Culture, History, Literature", Vol. 8oC (1980), pp. 109-158. 
MacWhite E., Vladimir Pecherin, 1807-1885: The First Chaplain of the Mater Hospital, Dublin, and the First Russian Political Emegré, "Studies: An Irish Quarterly Review", Vol. 60, No. 239/240 (Autumn-Winter, 1971), pp. 295-310.

MacWhite E., Vladimir Pecherin, 1807-1885: The First Chaplain of the Mater Hospital, Dublin, and the First Russian Political Emegré, "Studies: An Irish Quarterly Review", Vol. 61, No. 241 (Spring, 1972), pp. 23-40.

Mil'čina V.A., Ėpopeâ čelovečeskogo soznaniâ, [v:] Fransua Rene de Šatobrian. Zamogil'nye zapiski, Moskva 1995, s. 5-17.

Mozhajsky A. Yu., In the Footsteps of M.S. Koutorga, the First Russian Explorer of Boiotia, "Teiresias", Vol. 49 (part1), 2019, pp. 1-19.

Pečerin V.S., Opravdanie moej žizni: pamâtnye zapiski, "Naše nasledie" 1989, № 1, s. 61-77.

Pečerin V.S., Opravdanie moej žizni: pamâtnye zapiski, "Naše nasledie" 1989, № 3, s. 97-117.

Pečerin V.S., Statuâ Aleksandra Velikogo, "Kometa Bely" 1833, c. 257.

Pečerin V.S., Vzglâd na Tragedii Sofokla: Antigona i Aâks, "Syn Otečestva", T. XVIII, 1831, s. 351-3

Pečerin V.S., Zamogil'nye zapiski, Kalinin 1932.

Pervuhina-Kamyšnikova N.M., V.S. Pečerin: Èmigrant na vse vremena, Moskva 2006.

Plinij Staršij, Estestvennaâ istoriâ, kn. 34. http://annales.info/ant_lit/ plinius/34.htm, [data dostupa: 12.11.2019].

Scholl A., The Antikensammlung: 350 years of classical antiquity in Berlin, [in:] The Antikensammlung, Berlin 2016, pp. 7-18.

Ŝkin V.G., Russkoe zapadničestuo. Genezis - suŝnnost' - istoričeskaâ rol', Lodz' 2001. 